\title{
IMAGENS DE NAÇÃO EM AFRODIÇÕES LITERÁRIAS
}

\author{
Maria Nazareth Soares Fonseca \\ Pontifícia Universidade Católica de Minas Gerais
}

\begin{abstract}
Esse arquipélago do eu, o território psíquico do sincretismo, sob forma dialógica: de partes isoladas do meu eu, de minhas ilhas interiores, de meus rochedosde-carne, enseadas corporais, cavernas emotivas - antes que isolamentos - partem aventurosas pirogas, não somente para descobrir outros arquipélagos de outros eus, mas também para me deixar descobrir pelo olhar do outro. É ao me descobrir para o outro que me descubro.
\end{abstract}

Massimo Canevacci

afirmativa de Renan (1882) de que, sem o esquecimento
da violência que marcou a origem de todas as formações
nacionais, é impossível alcançar-se a unidade que as
constitui nos leva a admitir, como o faz Miranda (1997), que toda narrativa de nação se elabora a partir do jogo sutil entre lembrar e esquecer. Essa visão salienta o processo de negociação a ser assumido por projetos de identidade nacional, quando ressaltam o que deve ser retomado, porque constitui o exemplo a ser seguido, e o que precisa ser esquecido, para não contaminar o interesse geral, o bem comum a ser dignificado. É certo afirmar que as determinantes das formações nacionais consagram o esquecimento das diferenças como estratégia de suporte da ordem a ser implantada e que tal implantação se vale de uma pedagogia a ser sempre cultivada entre os cidadãos, como bem nos lembra Homi Bhabha (1994). A literatura, por vezes, mesmo quando produzida no calor das manifestações patrióticas, pode trilhar um caminho diferente e propiciar a emergência das vozes silenciadas. 
Tomando-se em consideração os processos de constituição do imaginário de nação e os modos como ele se representa na literatura produzida em espaços em que a dominação colonial se fez sentir até os meados do século atual, é possível perceber, na cena de textos literários, a produção de formas híbridas em que o discurso de nação aparece entrecortado por outras linguagens que desestabilizam a voz autoritária que encaminha uma pedagogia de ação identitária.

Estrategicamente, em espaços identificados por processo de formação de nacionalidades tardias, constróem-se diferentes percursos encaminhados por um tipo de literatura que se produz em espaços culturais onde a defesa de um projeto de nacionalidade se faz em meio a intensas contradições, advindas da diversidade étnica e de diferentes tradições. Nascida da necessidade de fortalecer sentimento de pertença e os anseios de liberdade, essa literatura, chamada "de combate", ressalta a proximidade entre a formação literária e a conscientização nacional. Em vários momentos, sendo veículo efetivo da propagação de feições identitárias, fortaleceu o ideal de formação de um território definido pelos valores da terra, origem da idéia de nação. Nessas construções literárias, a nação refletia-se enquanto lugar de concretização dos sonhos de liberdade, acalentados em meio a lutas ferrenhas contra um opressor comum. Entretanto, mesmo quando se destina à defesa de um bem para todos, tornados iguais, a palavra literária não se esgota naquilo que parece dizer e pode propiciar a disseminação de um outro propósito em que a busca da identidade nacional não se deixa cercear por intenções pragmáticas e imediatistas. A literatura faz-se desvio e se fortalece em construções mais identificadas com as expressões da oralidade, com os ritmos e gestos vivenciados pelo corpo em movimento. Significam esse processo alguns textos produzidos pelas literaturas africanas de língua portuguesa, nos quais o sentido político se constrói por um efetivo trabalho com a linguagem, que se faz inventiva e ágil, criadora de transgressões. A subversão do código, insistindo em evidências que fazem do português uma língua modelada pelos ritmos africanos, alude, por outros matizes, aos complexos processos de construção de nacionalidades ainda em 
formação. É a partir dessas literaturas que pretendo retomar alguns pontos da discussão sobre nação com o propósito de refletir sobre o lugar da literatura em projetos nacionais que estão se estruturando em meio às forças avassaladoras da globalização, aos processos de estreitamento das fronteiras entre o local e o geral.

Para discutir a relação entre literatura e projetos nacionais modernos que se organizam em universos de tradição ancestral, recorro a alguns pressupostos teóricos que possibilitam construir outras imagens de nação e destacar o trabalho da memória nas narrativas fundacionais.

Montserrat Guilbernau, em Nacionalismos: o estado nacional e o nacionalismo no século $X X,{ }^{1}$ discorda da idéia de que nação seja um fenômeno puramente moderno e aponta a existência dos mecanismos de harmonização e de apaziguamento das diferenças já na formação das grandes unidades que se desenvolveram na Europa Ocidental, depois da queda de Roma e da subseqüente desintegração do império carolíngio. Ao insistir nas raízes históricas da nação moderna, Guibernau salienta que "a estrutura dentro da qual a consciência nacional e a noção de pátria evoluíram na Europa estava estabelecida por volta do ano 1100". 2

É evidente que Guibernau não está se referindo apenas à origem do estado nacional reconhecido como unidade de um poder político por excelência, mas pensando esse estado a partir das raízes históricas de comunidades que se transformaram em nação e que, mais tarde, puderam ou não converter-se em estados nacionais. ${ }^{3}$ Por essa razão, ao se referir ao caráter político do nacionalismo, Guibernau propõe um distinção conceitual básica entre nação, estado, estadonacional e nacionalismo.

\footnotetext{
${ }^{1}$ GUIBERNAU, 1997.

${ }^{2}$ GUIBERNAU, 1997, p. 59.

${ }^{3}$ GUIBERNAU, 1997, p. 59.
} 
Por outro lado, ao questionar o conceito de nações naturais, proposto por Schleiermacher e Herder, comparando-o com as nações modernas, vistas como projetos políticos que desestabilizam formas de lealdade e de identidade de grupo, Guiberneau ressalta os mecanismos de controle e violência acionados pelo poder, percebendo-os como instituições típicas do Estado-Nacional. A distinção entre nação e Estado-Nacional, ainda que se reconheça o fato de que, na prática, a diferença entre os dois conceitos não se mostra com tanta clareza, é importante para a indagação da permanência das resistências identitárias no interior dos projetos nacionais e do papel da literatura quando toma para si a função de registrar a ambivalência da nação.

A visão de Frantz Fanon ${ }^{4}$ sobre a falência dos projetos nacionais, construídos a partir da ótica burguesa, reconhecida como unidade de poder político, ao reforçar a imagem da compartimentação do mundo colonizado, um mundo partido em dois, é importante para se refletir sobre as estratégias discursivas das narrativas de nação, produzidas nos intervalos, na intersecção de lugares demarcados. A imagem fanoniana torna-se pertinente para se pensar na ação pedagógica desenvolvida pelo discurso colonial e nas reversões que se produzem à revelia do poder. Ao insistir nas projeções que se produzem nos lugares fixos, desarticulando as antinomias, permite que se pense na metáfora de Babel, na profusão de discursos que, à revelia da voz autoritária que defende o controle necessário à eficácia da ordem, mostra-se no avesso daquilo que se diz. Assim Babel, significando "barulhamento" ensurdecedor das contradições silenciadas pelo controle das dissidências, evidencia outros modos de leitura das chamadas identidades nacionais. O traço marcante do processo identitário passa a ser lido a partir das digressões que dificultam a produção de um único sentido. De certa forma, é também Babel, figurada como entrelaçamentos e encruzilhadas,

${ }^{4}$ Cf. FANON, 1961. 
que se inscreve nas narrativas de fundação, mesmo quando elas fazem coro para o discurso hegemônico da nação, pois que, ainda assim, deixam aflorar imagens geradas pelo que falta ou pelo se perdeu. ${ }^{5}$

Para se pensar na desintegração dos discursos totalizadores e nas manifestações da diversidade que acompanham as operações de silenciamento operadas por - discursos fundacionais, é interessante recorrer à reflexão produzida por Édouard Glissant, da Martinica. Glissant retoma de algum modo as reflexões de Frantz Fanon, deslocando-as, entretanto, para a situação atual das relações culturais, na era da globalização. O teórico da Martinica discute os projetos de identidade nacional, utilizando-se do conceito de opacidade, tomado como signo de resistência ao processo diagnosticado por Frantz Fanon como um "princípio de exclusão recíproca", gerador da "constelação do delírio", que mediatiza as relações de poder no espaço colonial. ${ }^{6}$ No pensamento de Glissant, a opacidade seria, ao mesmo tempo, um elemento da criolização, de misturas, próprio dos espaços em que há acentuada presença da herança cultural africana, e uma forma de resistência à homogenização defendida por projetos nacionais e mesmo pelas redes de intercâmbio definidas pela globalização. Ao defender a idéia de movimentos relacionais não descaracterizadores da diferença, Glissant reforça a idéia de intercâmbio, mas rejeita a de aculturação.

Em Glissant, os conceitos de identidade raiz e de identidade relação viabilizam a releitura do universo da oralidade e propiciam a revitalização do "chaos-monde", mundo-caos, pensado como dissensão das dualidades ordem/desordem, oralidade/escrita. Com esse conceito o teórico investiga tanto as representações do imaginário de nação, quanto as que se elaboram no universo da Plantação, já pensada como "uma espacialidade transformada e

${ }^{5}$ Cf. MIRANDA, 1998.

${ }^{6}$ Cf. FANON apud BHABHA, 1998. 
socialmente concretizada". A partir daí, o teórico faz da criolização o significante por excelência das relações culturais heterogêneas, salientando os processos de mesclas culturais. Elaborando um pensamento teórico bastante peculiar, Glissant opera com uma significação mais ampla das tensões culturais, a partir das quais organiza a sua Poética da Relação. No cenário atual proposto pela globalização, as diferenças silenciadas pelo discurso hegemônico da nação são retomadas por ele para se pensar nos processos de produção das imagens fóbicas do outro (do negro, do nativo, do marginalizado), revitalizadas na época atual. Destacando os pontos de opacidade de sua cultura, Glissant ultrapassa os limites da nação martinicana e os da grande nação francesa, para construir uma visão de coletividade, que, próxima da de mestiçagem e da de globalização, não se quer em equivalência com elas. Na Poética da Relação, $a$ identidade cultural deixa de ser pensada como um dado da história íntima de cada grupo, de cada etnia, de cada nação, para ser percebida nos deslocamentos, no trânsito, na errância, na "dimensão cambiante e perdurável de toda mudança e de toda troca". ${ }^{8}$

De algum modo nos aproximamos desses deslocamentos, quando pensamos num tipo de literatura que se fortalece com as metáforas de Babel, com a simbologia das raízes aéreas, das redes e entrelaçamentos, para expressar identidades que se produzem em deslocamentos ainda que significadas pela ilusão da parada, do porto fixo. As metáforas glissanianas, raízes, redes, ramificação, constituídas em diálogo com o rizoma de Deleuze e Guattari, podem ser apreendidas em alguns, textos produzidos por escritores africanos de língua portuguesa como Luandino Vieira e Mia Couto, para se destacar apenas nomes já bastante conhecidos no Brasil. Reconhecidos pela abertura às línguas faladas em seus países e pelo

${ }^{7}$ SOYA, 1993.

${ }^{8}$ GLISSANT, 1996, p. 25.

${ }^{9}$ DELEUZE, 1995. 
investimento no trabalho com a linguagem, esses escritores insistem "nos atropelos que se possam fazer à língua clássica, à língua erudita", como bem acentua Luandino Vieira, ${ }^{10}$ para elaborar uma dicção política e subversiva que transgride a dimensão enunciativa dos textos. Esse trabalho de descentramento que tensiona a língua não cessa de conectar cadeias semióticas, como bem acentuam Deleuze e Guattari ${ }^{11}$ e também de subverter organizações de poder: a língua, a escrita modelar, os sentidos instalados.

Pode-se pensar, de um modo mais geral, em textos produzidos por Luandino Vieira e por Mia Conto, os quais se elaboram a partir de uma tensão instalada no interior do código lingüístico, no sistema da língua portuguesa. Tais textos poderiam ser vistos como narrativas de nação, pois aludem à construção de identidades nacionais, mas neles, os traços de identidade mostram-se como significantes de culturas compósitas, detalhadas em mosaico, por isso, sempre deslocados. Retomo, primeiramente de Luandino Vieira, João Vêncio: os seus amores, publicado em 1979, e Lourentinho, Dona Antónia de Sousa Neto $E$ eu, de 1981, para aludir a algumas construções que fazem desses textos espaço de conflitos identitários, cenário de confronto entre a tradição e os processos de inovação transportados para a África e ali fincados inexoravelmente para perdas e ganhos.

Em João Vêncio e na primeira novela de Lourentinho, Kinaxixi Kiami, a recuperação da memória é o traço que aproxima as duas narrativas. A figura de um narrador que elabora o seu relato no espaço da prisão é outro ponto que se relaciona nos dois textos. Um homicida, sexopata, sádico-hereje, acusado de homicídio frustrado é o narrador de João Vêncio; um assassino de um engenheiro que o obrigara a derrubar uma mafueira, o da novela Kinaxixi Kiami. As duas personagem aludem, de modo circunstancial, ao tempo de

\footnotetext{
${ }^{10}$ VIEIRA, 1987.

${ }^{11}$ Cf. DELEUZE, 1995, p. 16.
} 
prisão do escritor, no Tarrafal. Mas referem-se, em forma metafórica, à irremediável condição das nações emergentes, cujos projetos evidenciam, de forma mais intensa, as zonas de instabilidade, os labirintos da construção dissonante da nação.

A fala de João Vêncio, calcada em histórias contadas por um marinheiro pervertido, que falava mal português, misturado com quimbundo, inglês, espanhol, numa linguagem fabulosa, transforma-se "numa panorâmica muito lírica do homem do mundo colonial dividido, fragmentado", como testemunha o autor. Por esse viés, o caso individual é redimensionado pelo coletivo que, entretanto, não se agrega à visão triunfalista do discurso da nação emergente, embora esta também se mostre no texto. Uma colagem de discursos, um "colar de cores amigadas" constróem uma narrativa que se elabora como uma teia de relações, percursos em rede, amarrações, nos quais a memória escava um tempo no passado, para se recompor numa espacialidade. Operando num registro que denuncia, de um modo bem peculiar, a "instabilidade dos regimes de identificação" de que fala Miranda, ${ }^{12}$ João Vêncio se deixa possuir por uma fala alucinada, que é, ao mesmo tempo, signo e emblema uma vez que informa sobre (in)significâncias e anuncia, ainda que ilusoriamente, a possibilidade de resgate do que já não é mais. Daí que é sintomático o fato de que o narrador, em regime de exceção, na quionga, preso, construa um relato povoado por lampejos de terra, colo, aconchego, toques e cheiros, muitos cheiros, mas sempre deslocados, sempre em movimento: "tem a quinda, tem a missanga. Veja: solta, mistura-se: não posso arrumar a beleza que eu queria" (p. 13).

Diferentemente do resgate da memória que se configura pela linearidade, Luandino nos apresenta um texto crispado, que insiste numa infinidade de linhas de fuga, em giros, em interrogações: "Agora o mudié, me diga ainda: ser e não ser, ao mesmo tempo, pode-se? Gostar e não gostar, dor e alegria, água e fogo?” (p. 31).

${ }^{12}$ MIRANDA, 1997. 
Na ânsia de suturar um falta angustiante que mais se evidencia no contato com as leis e normas que o condenam, João Vêncio fala de amores que transitam pelas modulações de sua voz, escorregando em interditos, escorando-se provisoriamente nos sons e vozes desarticulados, facilmente percebidos em sua fala. Por isso, ao mesmo tempo em que se lança no passado, nele se perde, pois esse é um lugar de falsa ancoragem, um porto nenhum. Querendo-se inteiro, João Vêncio se anuncia outros, muitos, e é esse corpo sempre provisório que emblematiza o corpo plurissonante de sua cultura, aliás de todas as culturas, quando assumem a sua heterogeneidade. Na narrativa, revolvem-se restos e resíduos, cacos que não podem ser restaurados num só corpo, pois que são estilhaços, dilacerações significantes. É, portanto, no percurso da cegueira dos pássaros de olhos furados com a agulha de Maristrêla, (p.21), no timbre de uma fala que se anuncia na ordem do canto, ou no tateamento que estranha o gesto autoritário que se modelam os contornos da terra, o mapa ondulante de lugar, lugares, paisagens, em toda a sua desigualdade. ${ }^{13}$ A nação mostra-se no texto de Luandino Vieira no desassossego do seu próprio projeto.

De certa forma, é possível dizer-se que a revificação da memória que sustenta a identidade nacional está também em outros textos de Luandino Vieira, mas sempre de forma angustiada, pois, em vez da fixação narcísica no passado ancestral, impõe-se a abertura ao outro, a inscrição da dúvida, da interrogação e a impossibilidade de certezas mesmo que ilusórias.

No conto Kinaxixi Kiami que se delineia, como o próprio autor nos diz, como uma "peregrinação interior e geográfica de um mestiço" (1977), várias interrogações presentes em João Vêncio são retomadas e a questão da identidade é outra vez um lugar povoado de angústia:

${ }^{13}$ BERGER apud SOYA, 1993, p. 31. 
Em Kinaxixi fui nascido; lá morri; e me ressurgiram. Hoje nem sou mais sonho de nossa lagoa. Mas tempo teve nem nome eu que tinha, não usava coleira de papel. Era o eu; o tu; o ele - mais nada”. (KK. p. 12)

Esse ritual de desindividuação do sujeito e do lugar da enunciação de seu discurso está também em João Vêncio, apontando para a dissolução irremediável dos sentidos alocados, para a pulverização do significante, rastreando as manifestações de uma língua sem dono, prostibruta, perturbadora, caótica, babélica, que "não está no Gênesis, com todas as letras, efes-e-erros (... )" (KK. p. 20).

A construção da narrativa de significação individualista é, nessa novela, como em João Vêncio, problematizada. Mas não basta deslocar o "eu", substituí-lo pelo coletivo; o movimento que orquestra este tipo de texto e caracteriza sua feição literária não se restringe à simples permuta da voz enunciadora. O registro se faz de avanços e recuos: parece recompor, soldar, para novamente se soltar, deslocar, em sucessivos torneios. No corpo do texto, inscrevem-se giros, sempre giros, em espirais. O desconcerto nessas narrativas, ao desalojar uma perspectiva individualista, não instaura o império do coletivo; antes, aponta para a impossibilidade de qualquer harmonização, de qualquer contorno fixo, já que os percursos estão inscritos na inquietação, no transtorno, como significantes de zonas de instabilidade e de tormenta, que qualquer projeto de nação deseja ocultar:

Superstições gentias? Me cacimbou todo era com água-benta da missa da Missão de São Paulo, mamã. E fazíamos pelo-sinal. Contudo, desculpe o problema sempre não é esse - se sereia existe. Todo o problema, só um teorema: pessoa existe? De verdade mesmo - dono e patrão e escravo, sua a vida por conta e risco, livre de nada mais? (KK. p. 16).

Por isso, nessas narrativas e também em outras de Mia Couto, de Moçambique, observa-se a insistência em personagens que muito falam para aparentemente nada significar, já que "falar é babélica maldição" (KK, p.20). As certezas são antes incertitudes, trevas de solidão, interrogações, perguntas sem nenhuma resposta. 
Ainda que essas personagens possam por vezes ser identificadas com o narrador benjaminiano artesão ou viajante, ou com a tradição dos griots, numa cultura em que a oralidade sacraliza os relatos de sabedoria, são antes instâncias de dúvida, lugar de profundos conflitos. Esses narradores construídos em espaços de tradição ancestral já não contam histórias exemplares, pois só podem falar de perplexidades e de espantos. Expressam a ânsia de soltar uma fala reprimida, os sons desinventados, os barulhamentos, a profusão sonora do caos. Do caos-mundo, como nos observa Glissant.

É com esses movimentos sem direção marcada, sem porto de chegada, porque todas as certezas mostram-se como miragens, que se inscrevem as histórias de João Vêncio, as de Lourentinho e também a do preso sem nome do conto "Afinal Carlota Gentina não chegou de voar?”, de Mia Couto. Em todas essas histórias, a pontuação da identidade se faz pela interrogação de incertezas, pelo sentimento da fragmentação, pela experiência de um corpo criolo, no sentido apontado por Glissant, que se manifesta por gestos, voz, gritos, ruídos, palpitações de uma escrita pulsante. Uma "falescrita", expressão de um corpo que se quer em ressonância não apenas com um espaço cultural identificado, mas com a "simultaneidade e a extensão dos acontecimentos e das possibilidades". ${ }^{14}$ A obsessão pela palavra, pelo muito falar aparece marcada pela indefinição dos sentidos produzidos. Ou pela certeza de que falar não significa mesmo ser entendido por alguém de um mundo que se encosta no seu. Como explicar para o "doutor das leis" uma história calcada numa tradição que ele não conhece? E como se fundar nessa tradição se as marcas de pertencimento se diluem e o sujeito só pode se mostrar em bifurcações:

Porque dentro de mim, não sou sozinho. Sou muitos. E esses todos disputam minha única vida. Vamos tendo nossas mortes. Mas parto foi só um. Aí, o problema. Por isso, quando conto a minha história me misturo, mulato não de raças, mas de existências (p. 85).

${ }^{14}$ BERGER apud SOYA, 1993, p. 31. 
Não importa, por isso, que as questões formuladas ao interlocutor (o muadié em, João Vêncio, o companheiro de prisão em Kinaxixi Kiami!, o representante da lei em Carlota Gentina) sejam respondidas. O lugar da prisão, sendo o espaço das impossibilidades, é também um dos pontos da rede que liga pontos, faz interseções. ${ }^{15}$ É esse sentido que se salienta na fala do narrador do conto "Carlota Gentina", de Mia Couto, quando se afirma plural: "Porque dentro de mim não sou sozinho. Sou muitos. E esses todos disputam minha única vida." (p. 85).

Numa dicção mais coletiva, menos personalista, sempre deslocada, no entanto, a narrativa de nação, pelo menos em muitos exemplos da produção literária de alguns lugares da África portuguesa pode propiciar a retomada de questões que dizem respeito a modos diferenciados de percepção da cultura como algo constantemente em processo, em construção de simultaneidades. Este tipo de texto, por insistir no provisório, na precariedade dos signos, acata em sua feitura, os deslocamentos, as transgressões, mesmo quando se quer atrelado a projetos identitários e de afirmação de nacionalidades.

${ }^{15}$ FOUCAULT, 1986. 


\section{Referências Bibliográficas}

BHABHA. Homi K. O local da cultura. Trad. Míriam Ávila et al. Belo Horizonte: Editora UFMG, 1998.

CANEVACCI, Massimo. Sincretismos; uma exploração das hibridações culturais. Trad. Roberta Barni. São Paulo: Livros Studio Nobel Ltda, 1996.

COUTO, Mia. Afinal, Carlota Gentina não chegou de voar? In: Vozes anoitecidas. Lisboa: Caminho, 1987.

DAMATO, Diva. Edouard Glissant. Poética e Política. São Paulo: ANNABLUME/FFLCH, 1995.

DELEUZE, Gilles, GUATTARI, Félix. Mil Platôs - capitalismo e esquizofrenia. V. 1. Trad. Aurélio Guerra Neto e Célia Pinto Costa. Rio de Janeiro: Editora 34, 1995.

FANON, Frantz. Les damnés de la terre. Paris: Gallimard, 1961.

FOUCAULT, Michel. Of Other Spaces. Diacritics, 16, 22-27, 1986.

FONSECA, Maria Nazareth Soares. Contornos de nação literária no universo da "falescrita". In: Scripta Literatura. Vol. 1.n.2, Belo Horizonte: PUC-Minas, 1998. p. 140-153.

GLISSANT, Édouard. Poétique de la Relation. Paris: Gallimard, 1990.

GLISSANT, Édouard. Introduction à une poétique du divers. Paris: Gallimard, 1966.

GUIBERNAU, Montserrat. Nacionalismos; o estado nacional e o nacionalismo no século XX. Trad. Mauro Gama/Cláudia Martnielli Gama. Rio de Janeiro: Jorge Zahar, 1997.

LABAN, Michel. Encontros com Luandino Vieira, em Luanda. Lisboa: Edições 70, 1980.

LE GOFF. O desafio da mestiçagem. MAIS. 5 Caderno, Folha de São Paulo. São Paulo, domingo, 28 set. 1997.

MIRANDA, Wander Melo. Drummond no país do Mato-fundo. In: Revista da Biblioteca de Mário de Andrade. v. 55, jan./dez., 1997. p. 131-143. 
SOYA, Edward W. Geografias pós-modernas; a reafirmação do espaço na teoria social crítica. Trad. Vera Ribeiro. Rio de Janeiro: Jorge Zahar, 1993.

VIEIRA, José Luandino. João Vêncio: os seus amores. 2a. ed. Lisboa: Edições 70, 1987.

VIEIRA, José Luandino. Kinaxixi Kiami!. In: Lourentinho Dona Antónia de Souza Neto E eu. Lisboa: Edições 70, 1991.

\section{Resumo}

Discute-se a relação entre literatura e nação, tomando-se como referência tendências literárias expressivas das literaturas africanas de língua portuguesa. Salientam-se aspectos dessas literaturas que exibem, no trabalho com a linguagem, intensos conflitos entre projetos de nação e manifestações da tradição ancestral.

\section{Abstract}

This paper discusses the relationship between Literature and Nation taking as reference the impressing literary tendences from African Portuguese language literature. Aspects from this Literature are brought up showing at the work with language the intense conflicts between the Nation projects and the manifestations of ancestral tradition. 